\title{
ESTABILIDADE A OXIDAÇÃO DO DIESEL B PROVOCADO PELO BIODIESEL
}

\author{
Sergio Roberto Amaral ${ }^{1}$, Frederico Braz Silva ${ }^{2}$, Paulo Bertolini ${ }^{3}$, Marco Aurelio Bareira $^{4}$, \\ Marcos Marcondes ${ }^{5}$, Eduardo Abutara ${ }^{6}$, Francisco Carnizelo ${ }^{7}$ \\ ${ }^{1}$ MAN Latin America \\ ${ }^{2}$ MAN Latin America \\ ${ }^{3}$ MAN Latin America \\ ${ }^{4}$ MAN Latin America \\ ${ }^{5}$ TECCOM \\ ${ }^{6}$ TECCOM \\ ${ }^{7}$ TECCOM \\ sergio.amaral@volkswagen.com.br, frederico.silva@ volkswagen.com.br, \\ paulo.bertolini@volkswagen.com.br, marco.barreira@volkswgen.com.br,

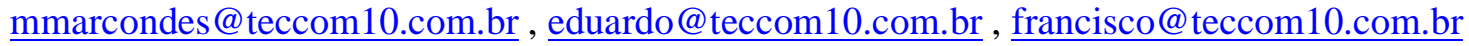

\begin{abstract}
Due to Brazilian vehicle sales characteristics that the specific condition depending of credit approval (financial system) and export timing period (boarding window), could promote the long lead time at sales yard at automakers companies could show some problems caused by fuel oxidation storage inside of vehicle fuel system. This condition (temperature and humidity variation) could accelerate the oxidation process. According to some diesel samples analysis, the oxidation basically starts after four months and increase exponentially belong the timing storage. Changing only the degraded fuel does not represent the problem solving because they are fixed at fuel tank wall, fuel filter saturated (pre filter and main filter) could increase a serious problem at injection system. The vehicle at this condition it will be expansive rework and beginning the losing money when the vehicle still keeping at sales yard, including parts changing, fuel replacement, hand work and customer delivery delay. Looking for this fuel problem scenario, were followed possible solution in order to stabilize the B Diesel (commercial Brazilian Diesel) inside vehicles at sales yard and keep this stability as longer as possible.

In this way, tests were performed with first fuel diesel used until this moment (same as found out at gas station - S10 B5) adding additive with stability characteristics according to additive maker information and were tested at same sales yard vehicles condition.

Fuel samples were collected according to time line defined previously and evaluating according to National Petroleum Agency (ANP) approval definition.

Tests were concluded after 15 months when we could confirm that all diesel characteristics are approved / preserved during all this period.

There were evaluated some vehicles stopped at sales yard at five months in average as well and were applied the same additive inside the main filter. We could also confirm the diesels at vehicle functionalities are according ANP approval.

Then, we could also reduce the total cost of ownership and warranty cost.
\end{abstract}




\section{INTRODUCÃO}

Atualmente o mercado de caminhões e ônibus que utilizam como fonte de combustível o diesel B, que possui a adição de biodiesel em porcentagem de mistura regulamentada/definida pela ANP, não apresenta perda de performance no motor e ou nos componentes do sistema de combustível dos veículos durante o uso continuo deste ou por necessidade de curtos intervalos de tempo que os veículos permaneçam parados. Entretanto, dentro dos pátios de venda da montadora, existem condições específicas que promovem a permanência dos veículos por prolongados períodos. Essa permanência representa basicamente o prazo de aprovação de financiamentos e de perda de janelas de exportação. Essas duas configurações impactam basicamente nos caminhões que podem chegar a ficar, em alguns casos, entre seis e doze meses parados nos pátios de venda da montadora. No caso dos ônibus as ocorrências se agravam pela parte de aprovação de financiamento e também pelo tempo de encarroçamento, que podem em alguns casos sofrer o mesmo tempo dos caminhões. Não obstante a isso, temos casos de veículos que ficaram um período menor nos pátios da montadora, cerca de três a quatro meses, e posteriormente repetindo esse intervalo nos pátios das concessionárias. Desta forma o custo se torna ainda maior, pois os valores são os definidos como trocas em garantia. Assim sendo, a mudança de Euro III para Euro V, onde foi reduzido o teor de enxofre visando atender as normas reguladoras de emissões, promoveu uma nova condição que anteriormente não existia. Verificamos que os veículos parados por esse longo período, deixavam de funcionar e ao abrir o sistema de combustível, encontramos uma borra de coloração escura que obstruía todo o sistema de injeção. Além disso, também foi encontrado o mesmo aspecto nos pré-filtro e filtro principal. Foi necessário criar sistema de inspeção, onde a cada três meses os veículos eram ligados por quinze minutos e a cada seis meses são substituídos o diesel e o pré-filtro e novamente deixando os mesmos ligados por mais quinze minutos, de forma a evitar atraso de entrega, possibilidade de multas contratuais e reiniciando o ciclo de inspeção. O impacto de custo referente a essa ação tornou-se inevitável. Essa configuração resultou em um aumento do custo operacional da empresa.

Visando reduzir esse custo, foram realizados testes com aditivos com o objetivo de estabilizar o óleo diesel ao biodiesel, prolongando o máximo possível às características do combustível e reduzindo os custos operacionais envolvidos em troca de componentes e de descarte dos resíduos sólidos. 


\section{IDENTIFICAÇÃO/BUSCA DE PRODUTOS}

Foi realizada uma busca no mercado brasileiro e europeu, com as informações que existiam até o presente momento, de forma a buscar contato com fabricantes de aditivos que possuíssem características de estabilidade do diesel ao biodiesel ou produtos já comercializados. Colocamos como informação inicial nosso objetivo de tempo, seis meses, com a preferência de ter um maior tempo possível de estabilidade.

Foram realizadas diversas reuniões, onde foram apresentados os produtos e os benefícios que possuíam. Foi deixado de forma clara que as nossas características geográficas poderiam influenciar nos resultados finais, porém não representará a ineficiência do produto testado.

Como a necessidade é específica para as condições da montadora e de tempo de pátio, não consideraríamos como produto reprovado aquele que não atendesse nossa necessidade. Indicaríamos como não atendendo a performance desejada.

Foi solicitado inicialmente que o produto tivesse a aprovação da ANP, e que a mistura do aditivo ao diesel B mantivesse todas as características de aprovação do combustível S10 B5.

\section{CONDIÇÕES DE TESTE}

A região geográfica da montadora permite variações climáticas elevadas de temperatura e humidade, que promovem a ocorrência de condensação dentro do tanque de combustível. Dessa forma, foram desenvolvidos suportes para que os tanques de combustível mantivessem a altura aproximada do veículo e que ficasse em local similar a configuração de pátio de vendas.

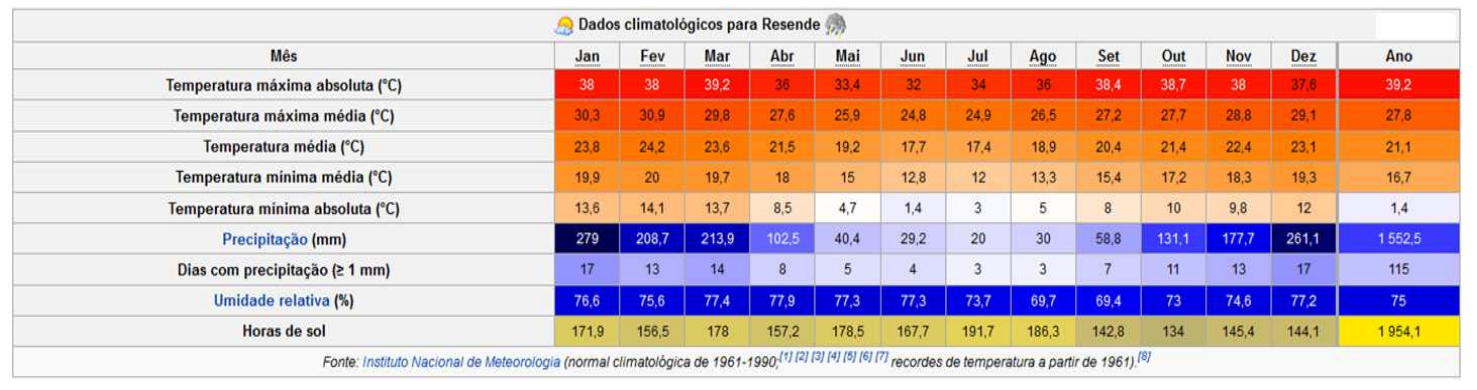

Tabela 1. Dados climatológicos de Resende RJ, conforme Instituto Nacional de Meteorologia.

Conforme os dados climatológicos da região de Resende - RJ, verificamos que as variações de mínima (próximo a zero grau) e máxima (próximo a quarenta graus) são grandes e a humidade relativa também é elevada (média anual de 75\%). Assim sendo, temos a melhor condição para um ambiente para a formação de condensação dentro do tanque de combustível. 


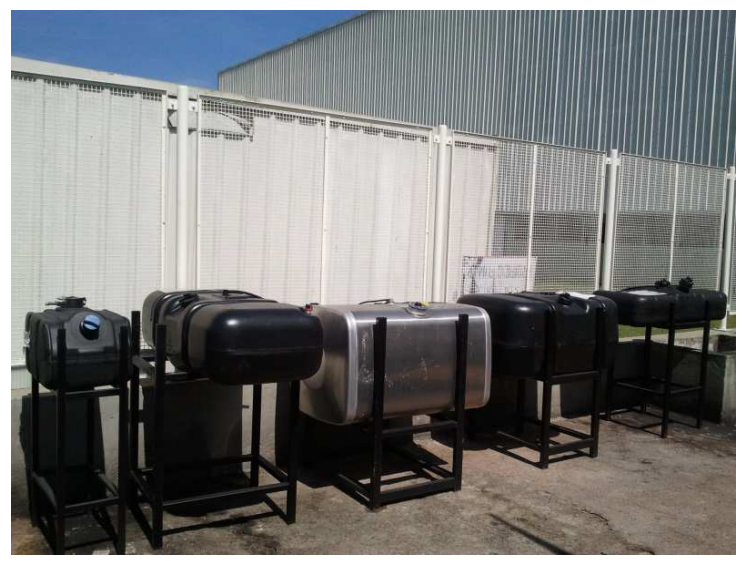

Figura 1. Todas as características tanques utilizados pela empresa foram avaliados come sem aditivo

As configurações de montagem foram respeitadas, ou seja: pescador, tampa e respiro aberto para o meio ambiente da mesma forma que o veículo final permanece no pátio de vendas.

\section{METODOLOGIA E RESULTADOS PARA A CONFIGURAÇÃO SEM ADITIVO}

Para que as condições ficassem mais realistas as existentes nos veículos que permanecem nos pátios de venda, foram segregados em área definida e com todas as condições de segurança necessários para testes em combustível aprovada pela equipe de segurança e meio ambiente da companhia, atendendo a lei de 12305/2010 da Política Nacional de Resíduos Sólidos, com área de contenção para inflamáveis e com restrição de entrada de pessoas, conforme Decreto 96.044/1988 / NBR's 7500; 7503; 9734 e 12710 / DZ-1310 R7, que estabelece o procedimento para carregamento para os resíduos contaminados, informando os responsáveis, o fluxo de trabalho, as atividades/indicadores e os documentos/registros que devem ser controlados e arquivados.

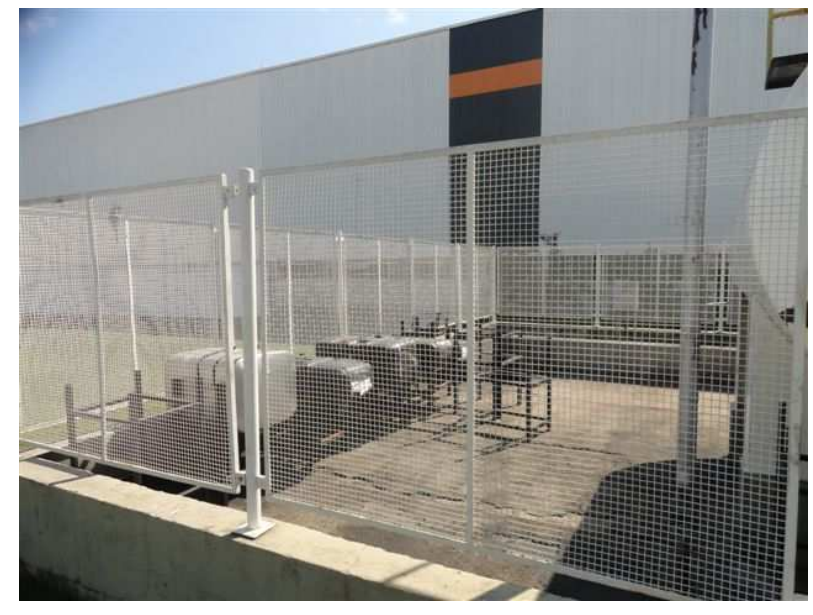

Figura 2. Área utilizada para testes com combustível 
O volume de abastecimento para cada tanque foi de 40 litros com intervalos de coletas previamente definido conforme linha de tempo da figura 3. Para tanto, cada coleta foi de 2 litros de Diesel e as analises seguiram fielmente a Resolução ANP número 50 de 23/12/2013.

As análises foram realizadas em tanques em iguais configurações contendo Diesel de primeiro abastecimento inicialmente sem nenhum tipo de aditivo.

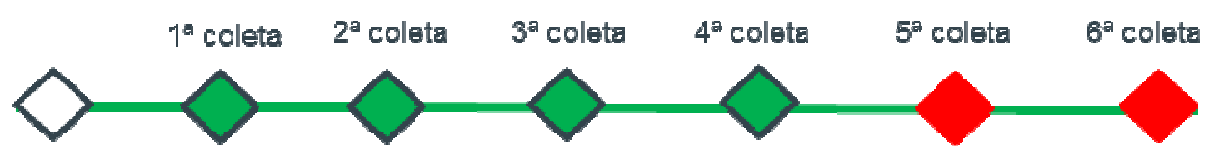

Figura 3. Linha de tempo para coletas/análises de Diesel de primeiro abastecimento sem aditivos.

\begin{tabular}{|c|c|c|c|c|}
\hline \multirow{2}{*}{ Ensaio } & \multicolumn{3}{|c|}{$\begin{array}{c}\text { Limite } \\
\text { Tipo A e B }\end{array}$} & \multirow{2}{*}{ Método } \\
\hline & S10 & \multicolumn{2}{|c|}{ S500 } & \\
\hline Destilação- $10 \%$ vol, recuperado $-{ }^{\circ} \mathrm{C}-\min$ & 180,0 & \multicolumn{2}{|l|}{-} & ABNT NBR 9619 \\
\hline Destilação- $50 \%$ vol., recuperado $-{ }^{\circ} \mathrm{C}$ & 245 a 295,0 & \multicolumn{2}{|c|}{245,0 a 310,0} & ABNT NBR 9619 \\
\hline Destilação- $95 \%$ vol., recuperado - ${ }^{\circ} \mathrm{C}$ - máx. & 370,0 & \multicolumn{2}{|l|}{-} & ABNT NBR 9619 \\
\hline Corrosividade ao cobre $3 \mathrm{~h}$ a $50^{\circ} \mathrm{C}$ & \multicolumn{3}{|c|}{1} & ABNT NBR 14359 \\
\hline Cor ASTM & \multicolumn{3}{|c|}{ Máx. 3,0 (2) } & ABNT NBR 14483 \\
\hline Viscosidade cinemática $40^{\circ} \mathrm{C}-\mathrm{mm}^{2} / \mathrm{s}$ & \multicolumn{3}{|c|}{2,0 a 5,0} & ABNT NBR 10441 \\
\hline Determinação de Água e Sedimentos - \% & \multicolumn{3}{|c|}{ Máx. 0,05 } & ASTM D 2709 \\
\hline Cor & (1) & \multicolumn{2}{|c|}{ vermelho } & Visual \\
\hline \multirow{4}{*}{ Ponto de entupimento de filtro a frio $-{ }^{\circ} \mathrm{C}-$ máx. } & Meses de Jan, & ar e Dez & 12 & \multirow{4}{*}{ ABNT NBR 14747} \\
\hline & Meses de Abr e & & 7 & \\
\hline & Meses de Mai, & le Ago & 3 & \\
\hline & Meses de Out e & & 9 & \\
\hline Teor de Biodiesel - \% & \multicolumn{3}{|c|}{$5 \pm 0,5$} & EN 14078 \\
\hline Teor de Enxofre-mg/kg-máx & 10,0 & \multicolumn{2}{|c|}{500} & ASTM D 5453 \\
\hline Aspecto & \multicolumn{3}{|c|}{ Límpido e isento de impurezas } & Visual \\
\hline Ponto de Fulgor $-{ }^{\circ} \mathrm{C}-$ máx & \multicolumn{3}{|c|}{38,0} & ABNT NBR 14598 \\
\hline Massa especifica a $20^{\circ} \mathrm{C}-\mathrm{kg} / \mathrm{m}^{3}$ & 815 a 850,0 & \multirow{2}{*}{\multicolumn{2}{|c|}{815 a 865,0}} & ABNT NBR 7148 \\
\hline Cinzas, máx. & 0,010 & & & ASTM D 482 \\
\hline
\end{tabular}

Tabela 2. Especificação, segundo Resolução ANP no 50 de 23/12/2013

As análises foram realizadas em laboratório neutro, de forma a não correr risco de resultados tendenciosos ou mascarados que pudessem ocorrer por parte do fabricante de combustível. Assim sendo, os resultados apresentaram uma tendência de aumento inicial de determinação de água e sedimentos conforme ASTM D 2709/96, a partir do quinto mês em todas as amostras avaliadas e aumentando em mais de três vezes para o mês seguinte. Foram coletadas quatro amostras mensais, totalizando 24 laudos, por um total de seis meses, nos quais identificaram uma característica de tendência deste combustível a perder propriedades, no caso um aumento de sedimentos, reprovando assim o combustível de acordo a resolução $\mathrm{n}^{\circ}$ 50 de 23/12/2013. 


\begin{tabular}{|c|c|c|c|c|c|}
\hline $\begin{array}{c}\text { Médias das } 4 \\
\text { amostras do Mês } 1\end{array}$ & $\begin{array}{c}\text { Médias das } 4 \\
\text { amostras do Mês } 2\end{array}$ & $\begin{array}{c}\text { Médias das } 4 \\
\text { amostras do Mês } 3\end{array}$ & $\begin{array}{c}\text { Médias das } 4 \\
\text { amostras do Mês } 4\end{array}$ & $\begin{array}{c}\text { Médias das } 4 \\
\text { amostras do Mês } 5\end{array}$ & $\begin{array}{c}\text { Médias das } 4 \\
\text { amostras do Mês } 6\end{array}$ \\
\hline 220,40 & 223,00 & 222,60 & 220,90 & 225,60 & 224,00 \\
\hline 282,60 & 282,60 & 283,10 & 281,70 & 284,30 & 283,00 \\
\hline 362,30 & 363,00 & 359,70 & 360,70 & 365,50 & 362,70 \\
\hline $1 \mathrm{a}$ & $1 \mathrm{a}$ & $1 \mathrm{a}$ & $1 \mathrm{a}$ & $1 a$ & $1 \mathrm{a}$ \\
\hline Cor ASTM L 1,5 & Cor ASTM L 1,5 & Cor ASTM L 1,5 & Cor ASTM L 1,5 & Cor ASTM L 1,5 & Cor ASTML 1,5 \\
\hline 3,285 & 3,25 & 3,291 & 3,184 & 3,274 & 3,241 \\
\hline 0 & 0,00 & 0,00 & 0,00 & 0,30 & 1,05 \\
\hline Amarelo & Amarelo & Amarelo & Amarelo & Amarelo & Amarelo \\
\hline-10 & -7 & -9 & -9 & -9 & -7 \\
\hline 5,23 & 5,34 & 5,31 & 5,24 & 5,31 & 5,32 \\
\hline 6,30 & 5,50 & 6,00 & 6,10 & 5,50 & 5,20 \\
\hline $\begin{array}{l}\text { Limpido e isento de } \\
\text { impurezas }\end{array}$ & $\begin{array}{l}\text { Limpido e isento de } \\
\text { impurezas }\end{array}$ & $\begin{array}{l}\text { Limpido e isento de } \\
\text { impurezas }\end{array}$ & $\begin{array}{l}\text { Limpido e isento de } \\
\text { impurezas }\end{array}$ & $\begin{array}{c}\text { Limpido e isento de } \\
\text { impurezas }\end{array}$ & $\begin{array}{l}\text { Limpido e isento de } \\
\text { impurezas }\end{array}$ \\
\hline 74,00 & 76,00 & 77,00 & 71,00 & 77,00 & 77,00 \\
\hline 839,20 & 839,90 & 839,90 & 839,20 & 840,00 & 840,00 \\
\hline$<0,001$ & $<0,001$ & $<0,001$ & 0,003 & 0,003 & 0,003 \\
\hline
\end{tabular}

Tabela 3. Média mensal das análises de Diesel de primeiro abastecimento sem aditivo.

\section{METODOLOGIA E RESULTADOS DE ESTABILIDADE PARA A CONFIGURAÇÃO COM ADITIVO}

Foram utilizados os mesmos procedimentos descritos no item 4. Inicialmente foram analisados cinco diferentes tipos de aditivos com realização de reuniões com cada um fornecedor onde foram apresentados as necessidades e os benefícios ofertados por seus respectivos produtos, porém para este trabalho em específico estaremos considerando apenas o que manteve estabilidade superior a seis meses e com a melhor performance. Desta forma, estamos reportando apenas o aditivo comercializado pela empresa TECCOM (Indústria e Comércio de Produtos Técnicos em Combustão Ltda.), com o nome: "TECCOM 10 Road Otimizador Bioestabilizador de Combustíveis".

Deve ser salientado que o produto que estamos levando como melhor performance não representa uma reprovação dos outros produtos testados.

A proporção de mistura utilizada para análise foi: 1:400 (um litro de aditivo para 400 litros de Diesel).

Admitimos então, que as médias apresentadas nas análises para a condição sem aditivo não mais atendia as configurações de aprovação pela Resolução ANP número 50 de 23/12/2013, a partir do quinto mês de estocagem.

Desta forma, a estratégia para a análise do diesel com aditivo foi alterada, pois foi considerado previamente que resultados inferiores aos cinco meses não mais interessavam. A necessidade está em prolongar por período superior, no caso o máximo possível, mantendo todas as condições de aprovação do combustível. A linha de tempo para essa configuração está apresentada na figura 4.

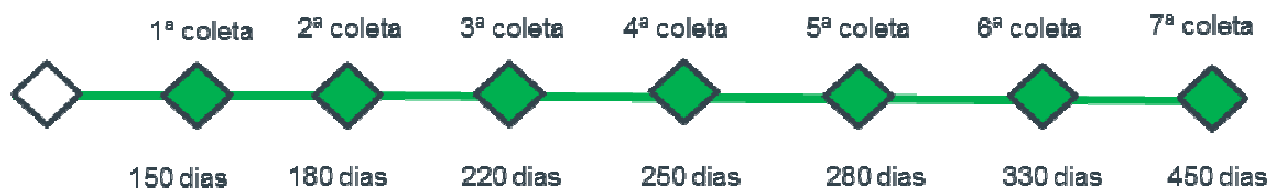

Figura 4. Linha de tempo para coletas/análises de Diesel de primeiro abastecimento com aditivo. 
O teste foi interrompido no final do decimo quinto mês, totalizando um período de 450 dias sem a alteração das propriedades do Diesel S10 B5 com a inclusão do aditivo conforme indicado na tabela 4 abaixo.

\begin{tabular}{|c|c|c|c|c|c|c|}
\hline $\begin{array}{c}\text { Médias das } 4 \\
\text { amostras - } 150 \text { dias } \\
\end{array}$ & $\begin{array}{c}\text { Médias das } 4 \\
\text { amostras - } 180 \text { dias }\end{array}$ & $\begin{array}{c}\text { Médias das } 4 \\
\text { amostras - } 220 \text { dias }\end{array}$ & $\begin{array}{c}\text { Médias das } 4 \\
\text { amostras - } 250 \text { dias }\end{array}$ & $\begin{array}{c}\text { Médias das } 4 \\
\text { amostras - } 280 \text { dias }\end{array}$ & $\begin{array}{c}\text { Médias das } 4 \\
\text { amostras }-330 \text { dias } \\
\end{array}$ & $\begin{array}{c}\text { Médias das } 4 \\
\text { amostras }-450 \text { dias }\end{array}$ \\
\hline 228,00 & 226,50 & 230,50 & 239,50 & 266,50 & 234,00 & 226,00 \\
\hline 290,00 & 287,50 & 285,50 & 284,50 & 283,00 & 283,00 & 285,00 \\
\hline 370,00 & 388,00 & 365,00 & 366,00 & 364,00 & 362,70 & 368,00 \\
\hline 1a & 1a & 19 & 19 & 1a & 19 & 1a \\
\hline CorASTML 1,5 & Cor ASTML 1,5 & CorASTML 1,5 & Cor ASTML 1,5 & CorASTML 1,5 & CorASTML 1,5 & CorASTML 1,5 \\
\hline 3,252 & 3,248 & 3,235 & 3,228 & 3,212 & 3,241 & 3,216 \\
\hline 0,00 & 0,00 & 0,00 & 0,00 & 0,005 & 0,00 & 0,00 \\
\hline Amarelo & Amarelo & Amarelo & Amerelo & Amarelo & Amarelo & Amare 10 \\
\hline$-2,00$ & $-2,00$ & $-2,00$ & $-2,00$ & $-2,00$ & $-1,00$ & $-1,00$ \\
\hline 5,25 & 5,20 & 5,25 & 5,37 & 5,34 & 5,82 & 6,28 \\
\hline 5,80 & 5,80 & 5,58 & 5,30 & 5,23 & 5,32 & 5,40 \\
\hline $\begin{array}{l}\text { Limpido e isento de } \\
\text { impurezas }\end{array}$ & $\begin{array}{l}\text { Limpido e isento de } \\
\text { impurezas }\end{array}$ & $\begin{array}{l}\text { Limpido e isento de } \\
\text { impurezas }\end{array}$ & $\begin{array}{l}\text { Limpido e isento de } \\
\text { impurezas }\end{array}$ & $\begin{array}{l}\text { Limpido e isento de } \\
\text { impurezas }\end{array}$ & $\begin{array}{l}\text { Limpido e isento de } \\
\text { impurezas }\end{array}$ & $\begin{array}{l}\text { Limpido e isento de } \\
\text { impurezas }\end{array}$ \\
\hline 59,00 & 60,00 & 60,00 & 61,50 & 65,50 & 64,80 & 62,50 \\
\hline 828,40 & 828,50 & 828,60 & 828,60 & 838,70 & 832,00 & 828,70 \\
\hline$<0,001$ & $<0,001$ & $<0,001$ & 0,001 & 0,001 & 0,001 & 0,001 \\
\hline
\end{tabular}

Tabela 4. Média mensal das análises de diesel de primeiro abastecimento com aditivo.

Foi identificado, a titulo de orientação do fabricante do aditivo, a tendência a manutenção dos dados de índice de lubricidade conforme ASTM D 6079 que indica o limite máximo permitido em $520 \mu \mathrm{m}$.

\begin{tabular}{|c|c|c|cc|c|c|}
\hline $\begin{array}{c}\text { Médias das } 4 \\
\text { amostras }-150 \text { dias }\end{array}$ & $\begin{array}{c}\text { Médias das } 4 \\
\text { amostras }-180 \text { dias }\end{array}$ & $\begin{array}{c}\text { Médias das } 4 \\
\text { amostras }-220 \text { dias }\end{array}$ & $\begin{array}{c}\text { Médias das } 4 \\
\text { amostras }-250 \text { dias }\end{array}$ & $\begin{array}{c}\text { Médias das } 4 \\
\text { amostras }-280 \text { dias }\end{array}$ & $\begin{array}{c}\text { Médias das } 4 \\
\text { amostras }-330 \text { dias }\end{array}$ & $\begin{array}{c}\text { Médias das } 4 \\
\text { amostras }-450 \text { dias }\end{array}$ \\
\hline 183,00 & 178,00 & 176,00 & 170,00 & 168,00 & 179,00 & 195,00 \\
\hline
\end{tabular}

\section{Tabela 5. Valores de tendência de lubricidade durante o teste com aditivo}

Os dados coletados indicam uma tendência à estabilidade a lubricidade no período analisado, comprovando a informação do fabricante de aditivo.

Foi realizado teste de opacidade entre o diesel comercial e o aditivado, onde foi verificado que mantiveram as mesmas características. Foram realizadas duas rodagens, nomeando os dois abastecimentos como Reagente 1 e Reagente 2 . O limite de opacidade perante a NBR 13037 é de 1,19 porém a empresa trabalha com critério de aprovação máximo de 0,9 para mercado doméstico e de 0,7 para países com altitude elevada (acima de 4000 metros). Desta forma o aditivo utilizado não altera a condição já existente, conforme tabela 6 abaixo:

\begin{tabular}{|c|c|c|c|c|c|c|c|c|c|}
\hline & \multicolumn{3}{|c|}{ Baseline } & \multicolumn{3}{|c|}{ Reagente 1} & \multicolumn{3}{|c|}{ Reagente 2} \\
\hline Testes & Teste 1 & Teste 2 & Teste 3 & Teste 1 & Teste 2 & Teste 3 & Teste 1 & Teste 2 & Teste 3 \\
\hline \multirow{10}{*}{ Opacidade } & 0,52 & 0,5 & 0,51 & 0,43 & 0,48 & 0,5 & 0,53 & 0,43 & 0,46 \\
\hline & 0,5 & 0,48 & 0,4 & 0,49 & 0,41 & 0,39 & 0,49 & 0,42 & 0,35 \\
\hline & 0,58 & 0,49 & 0,42 & 0,45 & 0,39 & 0,44 & 0,59 & 0,44 & 0,42 \\
\hline & 0,49 & 0,5 & 0,41 & 0,45 & 0,42 & 0,4 & 0,56 & 0,44 & 0,42 \\
\hline & 0,48 & 0,46 & 0,42 & 0,52 & 0,38 & 0,44 & 0,52 & 0,49 & 0,45 \\
\hline & 0,47 & 0,47 & 0,34 & 0,5 & 0,41 & 0,38 & 0,49 & 0,46 & 0,44 \\
\hline & 0,5 & 0,43 & 0,48 & 0,46 & 0,4 & 0,44 & 0,57 & 0,45 & 0,47 \\
\hline & 0,55 & 0,43 & 0,38 & 0,44 & 0,4 & 0,38 & 0,47 & 0,46 & 0,46 \\
\hline & 0,42 & 0,45 & 0,38 & 0,48 & 0,46 & 0,38 & 0,55 & 0,43 & 0,42 \\
\hline & 0,42 & 0,41 & 0,35 & 0,48 & 0,38 & 0,38 & 0,44 & 0,45 & 0,43 \\
\hline Média & 0,491 & 0,462 & 0,409 & 0,47 & 0,413 & 0,413 & 0,521 & 0,447 & 0,432 \\
\hline \begin{tabular}{|l|} 
Média Total \\
\end{tabular} & \multicolumn{3}{|c|}{0,45} & \multicolumn{3}{|c|}{0,43} & \multicolumn{3}{|c|}{0,47} \\
\hline
\end{tabular}

Tabela 6: Análise de opacidade entre o diesel comercial e duas amostras aditivadas. 


\section{METODOLOGIA APLICADA PARA VEÍCULOS PARADOS NO PATIO COM MAIS DE QUATRO MESES}

Devido à necessidade de entrega de veículos e evitando a penalização por atraso, foi realizado, inicialmente, teste em veículos parados em pátio de vendas por um período superior a cinco meses, considerando inclusive aqueles que realizaram os procedimentos de pátio, referentes a troca de combustível, porém já estava a cinco meses com o mesmo diesel e já apresentavam falhas na partida ou não davam a partida. Foram feitas avaliações visual no diesel dentro do tanque, filtro do pescador, filtro principal e bicos injetores, onde verificamos que os mesmos possuíam a formação de borras com aspectos de "verniz ou goma" que indicavam serem os agentes impeditivos do funcionamento do veículo.

Segundo as orientações do fabricante do aditivo, foram colocados $400 \mathrm{ml}$ de aditivo no filtro principal e $200 \mathrm{ml}$ no tanque de combustível principal, totalizando $600 \mathrm{ml} /$ veículo.

Foi feito uma análise da reação do filtro do pescador com o aditivo, avaliando as informações de solubilização do "verniz ou borra" indicadas pelo fabricante de aditivo.

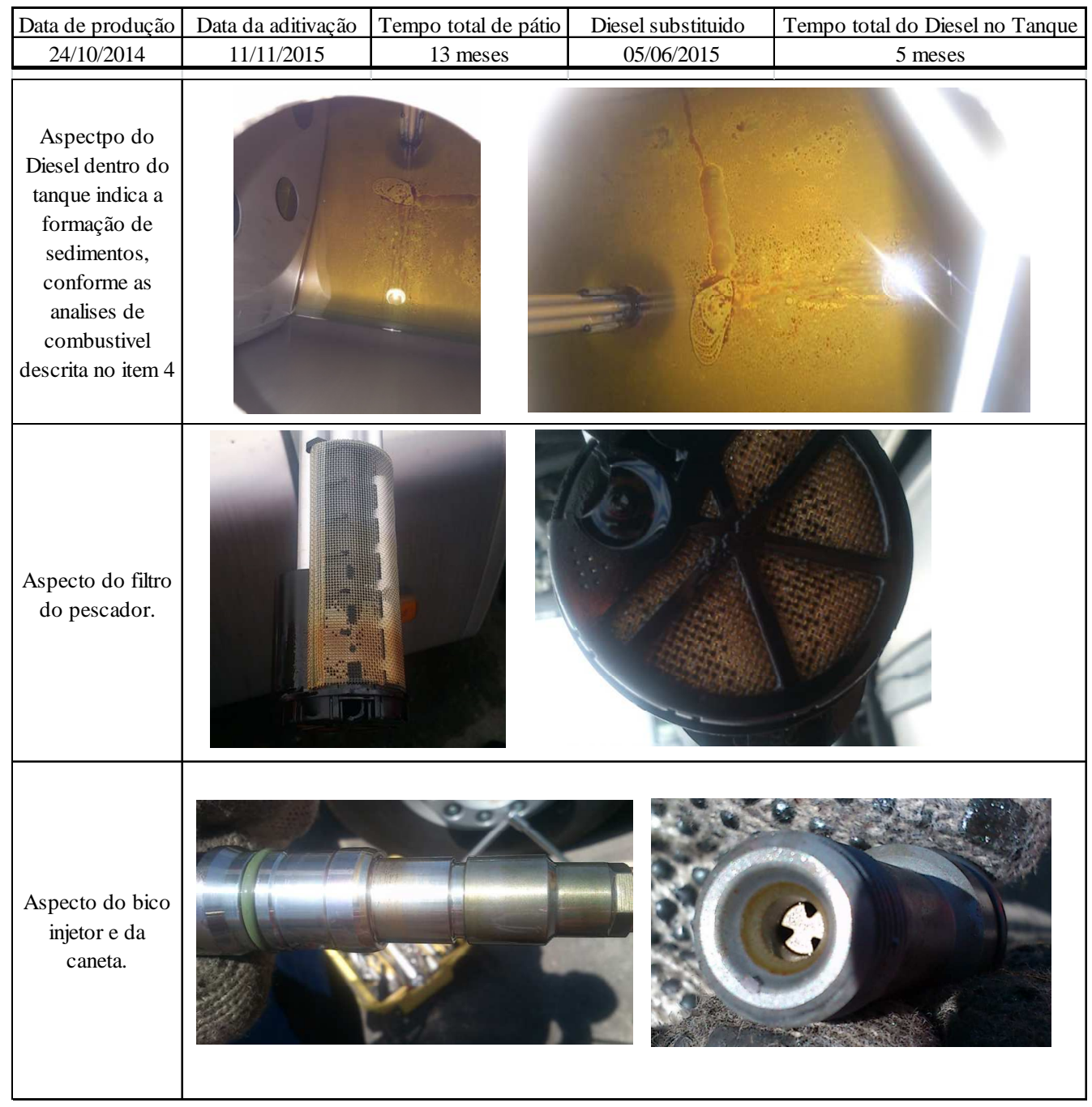

Tabela 7. Indica a característica dos componentes em veículo de pátio de vendas com diesel parado por 5 meses dentro do sistema de combustível. 
O procedimento utilizado apresentou inicialmente uma diferença visual significativa nas peças com contato/ação do aditivo. O efeito também foi verificado nos veículos que não conseguiam dar a partida e após a aplicação do aditivo obteve funcionamento normal.

Após a partida do veículo, o mesmo manteve em funcionamento por 20 minutos, de forma a fazer circular o aditivo nas linhas de injeção para que possa atuar nos componentes. Após esse período, foi realizada nova avaliação visual para efeito de comparação, conforme tabela 8 abaixo.

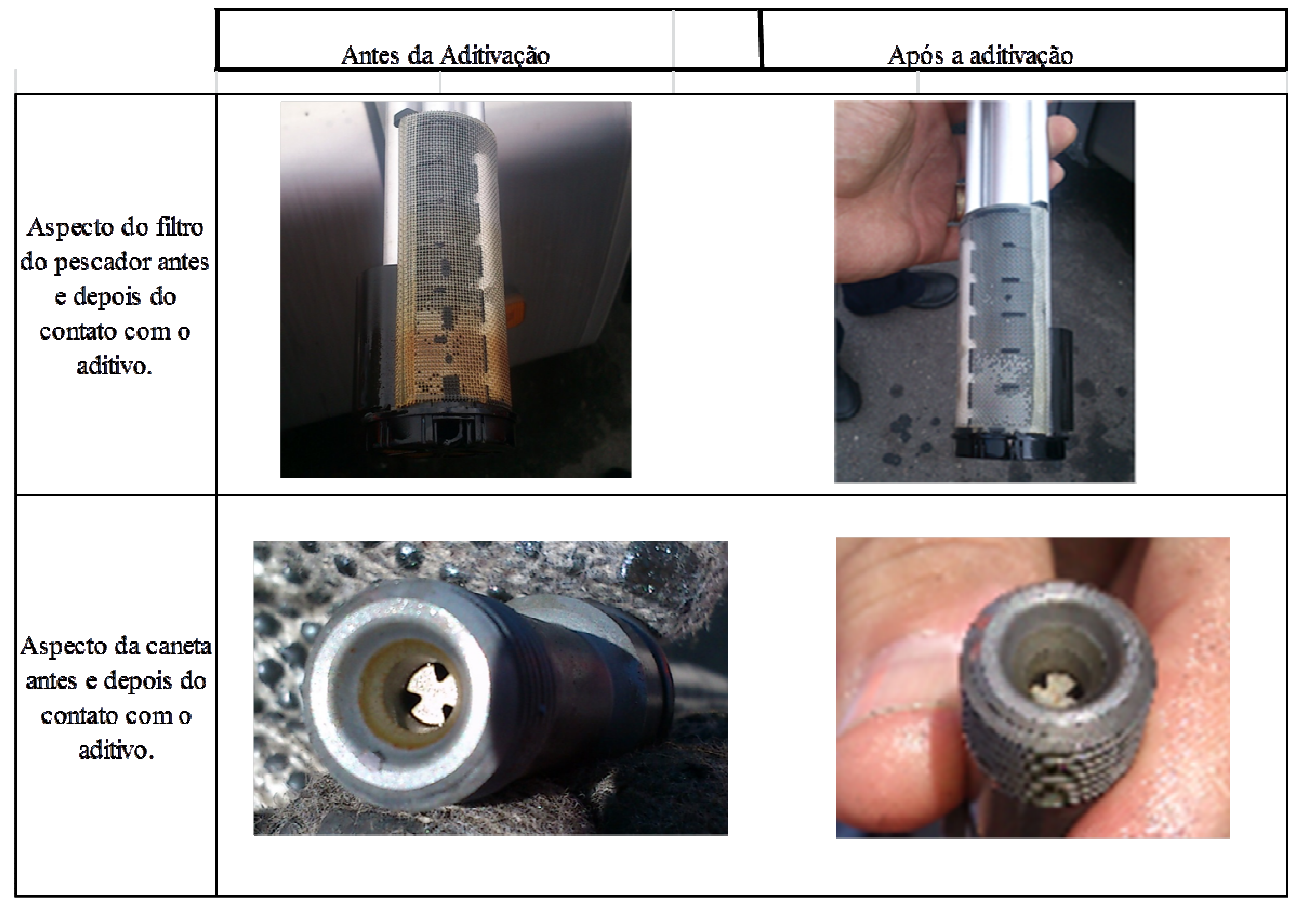

Tabela 8. Indica a característica dos componentes em veículo de pátio de vendas com diesel parado por 5 meses dentro do sistema de combustível após a aditivação.

Foi retrabalhado um total de 50 veículos tratores de mesma característica de torque e potência, porém de aplicações e de localizações de venda distintas, em termos de Brasil. Os veículos estão sendo rastreados para que seja avaliada a confirmação da eficácia do produto até a entrega do mesmo ao cliente final, sem a necessidade de haver troca de nenhuma peça do sistema de combustível em garantia. Esta aditivação ocorreu em Novembro de 2015, todos os veículos voltaram a funcionar normalmente e permaneceram em funcionamento por 15 minutos. Todos foram liberados para venda, onde até o presente momento não obtivemos reclamações/custo de garantia envolvendo os mesmos.

\section{CONCLUSÕES}

- Foi possível verificar que o diesel comercial com 5\% de biodiesel inicia, em média, as perdas de propriedades, conforme resolução ANP 50 de 23/12/2013, a partir do quinto mês, conforme resultados apresentados na tabela 3 , onde verificamos que ocorre a aceleração da formação de sedimentos, e comprovado visualmente em tanque de combustível de veículo controlado no pátio de vendas, conforme imagem da tabela 6 . Considerando que o local/região avaliado possui características climatológicas que tendem a acelerar o processo de degradação do combustível, devido a grande variação 
de temperatura (máxima e mínima), aliada a uma elevada característica de umidade relativa anual de $75 \%$ em média, conforme tabela 1 , cria-se uma condição de condensação propícia para a aceleração da formação de sedimentos.

OBS: Essa condição não significa que em outras localidades o processo de degradação tenha a mesma tendência de tempo. Como a região testada possui uma variação que apresenta uma característica muito crítica, consideramos que esses resultados possuam uma confiabilidade muito elevada com relação ao tempo de degradação do diesel e com potencial para ser referência para o mercado nacional.

- As avaliações do aditivo utilizado para estabilizar a formação do diesel ao biodiesel mostrou uma condição de aprovação, seguindo os mesmos critérios ANP descritas neste trabalho, de 15 meses sem a ocorrência de formação de sedimentos/degradação.

- Não houve alteração em teste de opacidade realizada, comparando a configuração com e sem aditivos. As médias dos resultados ficaram dentro do praticado pela empresa para aprovação.

- Os veículos parados no pátio de venda, devido aos procedimentos de liberação de financiamento e outras configurações de venda, por mais de cindo meses e que estavam sem dar partida, voltaram a operar normalmente após a aditivação, conforme descrito no item 6 .

- Após a confirmação do funcionamento da aditivação, foi realizada a liberação do uso do aditivo para todo backlog existente, de forma a evitar o custo de troca de peças na fábrica e em garantia.

- Essa configuração promove à redução de custos operacionais da empresa ligados a troca de combustível, de sistema de injeção, filtros e pré-filtros dos veículos nos pátios de venda, além de reduzir o custo de garantia dos veículos que estão nas concessionárias e acabam tendo um prazo elevado de tempo para serem adquiridos. Esta configuração ainda impacta na redução de descarte de resíduos sólidos.

\section{REFERÊNCIAS BIBLIOGRAFICAS}

[1] BRUNETTI, F.; Motores de Combustão Interna, Volume 1, São Paulo, editora Blucher, 2012 .

[2] BIODIESEL. GOV. Legislação e Normas sobre Biodiesel. 2005. Disponível em: http://Bolsista de Valor: Revista de divulgação do Projeto Universidade Petrobras e IF Fluminense v. 2, n. 1, p. 49-53, 2012, www.biodiesel.gov.br/legislacao.html: acesso em maio de 2013

[3] BIODIESEL. Wikipedia. Disponível em: 〈http://www.pt.wikipedia.org/wiki/Biodiesel>.

[4] BUENO, A. V.; Análise da operação de motores diesel com misturas parciais de biodiesel. Campinas: UNICAMP, 2006.

[5] McCORMICK, R .L.; WESTBROOK, S. R.; Storage stability of biodiesel and biodiesel blends, Energy Fuels, 24 (2010), pp. 690-698 
[6] YAMANE, K; KAWASAKI, K.; SONE, K.; HARA, T; PRAKOSO, T.; Oxidation stability of biodiesel and its effect on diesel combustion and emission characteristics, Int J Engine Res, 8 (2007), pp. 307-319

[7] JAIN, S.; SHARMA, M.P.; Stability of biodiesel and its blends: a review, Renew Sustainability Energy Rev, 14 (2010), pp. 667-678

[8] BONDIOLI, P.; GASPAROLI, A.; LANZANI, A.; FFEDELI, E.; VERONESE, S.; SALA, M.; Storage stability of biodiesel, J Am Oil Chem Soc, 72 (1995), pp. 699-702

[9] Agência Nacional de Petróleo, Gás Natural e Biocombustíveis. Resolução ANP 50 de $23 / 12 / 2013$

[10] Agência Nacional de Petróleo, Gás Natural e Biocombustíveis. Resolução ANP 69 de $23 / 12 / 2014$

[11] Instituto Nacional de Meteorologia - Dados Climatológicos de Resende - RJ, disponível em http://www.inmet.gov.br/portal/: acesso em março de 2012 